\title{
A GEOGRAFIA UNIVERSITÁRIA EM ÉPOCA DE BENCHMARKING
}

Teresa Barata SAlgueiro ${ }^{1}$

Resumo - O processo de Bolonha vem introduzir dimensões novas na reflexão sobre a organização dos cursos universitários. Procuramos dar um contributo para esta questão focando essencialmente três aspectos: o aumento da concorrência entre escolas, o tipo de inserção profissional possibilitada pelo primeiro ciclo de estudos e, intimamente ligado com isso, as competências que os alunos devem adquirir com o curso. Finalmente, abordamos a questão dos métodos de ensino e suas repercussões na estrutura dos cursos.

Palavras-Chave: Processo de Bolonha, reestruturação do curso, ensino-aprendizagem.

Abstract - Geography in Higher educATion age of BENCHMARKING. The Bologna process has brought some new dimensions to the discussion around the structure and organization of university degrees. The aim of this paper is to contribute to this discussion by focusing on three particular aspects: the increase in the level of competition between the schools, the type of labor market access rendered possible by the first cycle of studies and, in close relationship with the latter aspect, the issue of the skills and competences that the students are supposed to have acquired upon ending their university studies. Finally, we address the issue of the teaching methods and their repercussions upon the structure of the courses.

Key words: Bologna process, reorganization of the course, learning outcomes.

Résumé - La GÉOgRAPHIE UNIVERSITAIRE EN ÉPOQUe DE BENCHMARKING. Le processus de Bologne a introduit de nouvelles dimensions dans la réflexion sur l'organisation de l'enseignement universitaire. On traite ici fondamentalement trois aspects: la concurrence accrue entre les écoles, le type d'insertion professionnelle permis par le premier cycle des études et, en conséquence, les compétences que doivent alors acquérir les élèves. Puis on aborde la question des méthodes d'enseignement et de leur répercussion sur la structure des cours.

Mots-clés: Procès de Bologne, réorganisation des cours, enseignement-apprentissage.

1 Professora Catedrática na Universidade de Lisboa, FLUL, e Investigadora no Centro de Estudos Geográficos. E-mail: tbs@fl.ul.pt 


\section{INTRODUÇÃO}

Até aos anos 70 a Geografia universitária é ensinada nas Faculdades de Letras das Universidades de Lisboa e Coimbra, que conferem graus académicos segundo o mesmo plano de estudos, havendo ainda ensino de matérias geográficas nas Faculdades de Arquitectura, Ciências Sociais e Políticas, Economia e outras, por vezes assegurado por não geógrafos.

Desde 1968 o curso de Geografia compreendia 2 níveis, o de bacharel com 3 anos e o de licenciado com mais 2 e uma dissertação; este grau era necessário para prosseguir a carreira académica, enquanto o primeiro era suficiente para a profissionalização como docente do ensino básico e secundário. Com esta reforma extinguiram-se os cursos de professores adjuntos, cursos curtos criados em 1948 que davam qualificação para acesso ao estágio no ensino não superior, mas apenas nas escolas do ciclo preparatório e do ensino técnico. A Geografia enquadrava-se no grupo que tinha um perfil de 'ciências', o 11. . Este modelo, tal como a criação dos bacharelatos em 1968, visava produzir mais depressa e com menos custos docentes para o ensino secundário, então em grande expansão.

Em termos de duração de estudos, o bacharelato teve pouco sucesso em Letras, na medida em que a maioria dos estudantes fazia os cursos de 5 anos, servindo basicamente para fornecer um diploma àquela percentagem muito significativa que completava os 5 anos curriculares mas não fazia a tese e, por isso, não ficava licenciada.

As décadas de 70 e 80 foram períodos de forte expansão da geografia universitária nas suas diversas vertentes, na sequência de um processo que já vinha da segunda metade dos anos 60 e está suficientemente documentado e comentado ${ }^{2}$. Cresceu o número de estudantes, de docentes, de graduados nos diversos níveis, incluindo doutores, o número de departamentos de geografia, de faculdades e cursos onde se ministrava este ensino. A transformação não foi apenas de tipo quantitativo, pois incluiu igualmente aumento da diversificação na organização dos cursos, como na introdução de novos temas de estudo e de novas perspectivas analíticas. Alargou-se o leque de saídas profissionais ${ }^{3}$ e alteraram-se as condições do mercado de trabalho, agora menos definido, o que contribuiu também para aumentar a pressão no sentido de diversificar a oferta de formação na universidade.

Como instituição social a universidade é palco das tendências, crises e conflitos que atravessam a sociedade, mas o peso da antiguidade e a forte inércia arrastam dificuldades em antecipar a mudança. Mesmo assim, a Geografia dos

2 Podem ver-se os importantes trabalhos de Amaral, Medeiros e Gaspar, Gaspar e Ferrão, Barata Salgueiro, Claudino, entre outros

3 Sintoma desta realidade e da maior presença de geógrafos na sociedade portuguesa foi a constituição da Associação Portuguesa de Geógrafos (APG) em 1987. 
últimos 30 anos viu instituir práticas quase permanentes de transformação e de avaliação, muito importantes em termos de reconfiguração face aos novos desafios. Os anos de 74 a 76 foram anos de grande turbulência e de enorme riqueza no domínio do ensaio de novos temas a pesquisar e ensinar, da organização curricular, dos métodos de ensino que, mesmo depois da normalização, nos deixaram o gosto pela alteração frequente de processos. Sendo positiva a abertura à mudança não deixa de ser importante registar que nem sempre ela tem resultado de uma correcta avaliação da situação anterior e que alterações muito frequentes criam instabilidade e dificuldades às organizações, especialmente aquelas, como a FLUL (Faculdade de Letras da Universidade de Lisboa), que tinham enormes deficiências no domínio do pessoal não docente. De modo semelhante, ineficiência das instituições impede certas inovações como a de introduzir aquilo que aparentemente todos dese-jámos sempre, um curso quase totalmente livre e flexível, baseado predominantemente em disciplinas de opção.

As várias reformas registadas pela Geografia da FLUL, principalmente a introdução de novos temas e perspectivas, beneficiaram da experiência internacional, que os membros da equipa docente tinham adquirido nos seus numerosos contactos, adaptada às necessidades internas, isto é, às características do mercado de trabalho, também ele a sofrer importante mutação. De facto, nos últimos 30 anos assistiu-se ao estreitamento progressivo do destino tradicional dos estudantes representado pelo ensino secundário e a abertura de outras oportunidades profissionais, no planeamento do território, na gestão e protecção de recursos naturais, na protecção civil, em gabinetes de estudos com incidência territorial, no turismo, entre outros. GASPAR e MEDEIROs (1982), comentando as experiências realizadas entre 1974 e 1977 na FLUL, dizem que o objectivo foi «acertar o passo rapidamente com o que se fazia nas universidades estrangeiras onde os geógrafos mais se distinguiam e transformar a Geografia numa disciplina ao serviço da comunidade» o que subentende a perspectiva da aplicação.

No momento presente de reestruturação dos cursos, a componente externa, consubstanciada no esforço de concertação conhecido como processo de Bolonha, é muito importante e vem introduzir dimensões novas na reflexão. Em primeiro lugar com Bolonha vai aumentar a concorrência entre escolas o que obriga desde logo a posturas diferentes quando se pensa em reestruturação. Assim, no primeiro ponto chamamos a atenção para este facto e sugerimos algumas vias a ter em consideração. A segunda questão prende-se com o tipo de inserção profissional possibilitada pelo primeiro ciclo de estudos e, intimamente ligado com ela, a das competências que os alunos devem adquirir com o curso. Finalmente, em terceiro lugar, abordamos a questão que nos parece mais importante, a dos métodos de ensino e suas repercussões na estrutura dos cursos. O exemplo usado é, naturalmente, o do curso de Geografia na Faculdade de Letras de Lisboa.

Consciente de que estamos de novo num importante tempo de balanço e de interrogações, procuramos com este texto dar um contributo à discussão, homenageando Carlos Alberto Medeiros que durante os 8 anos em que foi vice-reitor 
da Universidade de Lisboa (1990-98), para além de professor, esteve empenhado nas questões da gestão da Universidade, e sempre deu um valioso contributo aos debates para a reestruturação da Geografia na FLUL.

\section{CONCORRÊNCIA E RELEVÂNCIA SOCIAL}

O objectivo proclamado do processo de Bolonha é contribuir para a construção de um espaço europeu de ensino superior que, por um lado promova a mobilidade e a empregabilidade entre cidadãos europeus e, por outro lado, eleve a competitividade internacional do sistema ${ }^{4}$. Grande parte dos documentos produzidos têm focado os aspectos da comparabilidade dos cursos para facilitar a mobilidade dos estudantes, mas existe também um objectivo menos explícito de economia de recursos. De facto, com a generalização do ensino de massas e a tendência para aumentar os anos de escolaridade, de modo que a médio prazo em muitos países percentagem considerável da força de trabalho tenha o primeiro ciclo universitário, em simultâneo com a tendência para reduzir o investimento público na reprodução social em geral e no ensino superior em particular, a redução dos ciclos de estudos universitários visa igualmente poupar investimentos públicos e as despesas das famílias com a formação dos jovens, agora com possibilidade de ser efectuada em ciclos autónomos e desconectados no tempo.

Uma das consequências do incremento da mobilidade é o aumento da concorrência e o maior contributo das universidades e departamentos para a diferenciação dos níveis hierárquicos dos lugares num sistema supranacional. É de esperar que se venha a assistir a uma relativa uniformização do primeiro ciclo do ensino superior, banalizado e oferecido em muitos pontos do território, de forma quase dispersa, mesmo se algumas escolas se destaquem pela sua maior qualidade, e um progressivo estreitamento de uma oferta muito competitiva nos níveis mais altos. Serão menos as universidades, as mais centrais, de grande qualidade e atractividade a oferecer os diplomas mais desejados. Elas terão mais alunos, poderão cobrar propinas mais altas, terão mais dinheiro, portanto, também melhores recursos humanos e materiais e contribuirão activamente para o posicionamento da cidade onde se instalam no sistema urbano. Isto vai exigir às universidades e cursos posicionamentos pró-activos, práticas de benchmarking, selecção cuidada de apostas estratégicas em cursos, modelos, e professores capazes de atrair alunos, dar ou reforçar o seu prestígio e, por tudo isso, a cobrar mais pelo ensino.

Neste quadro competitivo, Portugal é bastante prejudicado pela posição geográfica e pela língua, embora disponha também de algumas vantagens como

4 Declaração dos Ministros da Educação Europeus reunidos em Bolonha em 19 de Junho de 1999. 
investigação de bom nível, prestígio nalgumas áreas de conhecimento, bom clima e qualidade ambiental, preços relativamente acessíveis, facilidade de relacionamento com o Sul, principalmente com o Brasil e a África.

$\mathrm{Na}$ discussão presente importa pensar cursos que interessem aos europeus, e não apenas aos portugueses, bem como ter presente que, para além da qualificação dos cidadãos nacionais, podemos desempenhar um importante papel na qualificação dos recursos humanos da África e mesmo do Brasil, função que importa esclarecer. Esta reflexão não é fácil, face ao pouca hábito de olhar para fora sem ser para importar modelos e de avaliar as nossas possibilidades fora do quadro geográfico nacional. Se não quisermos perder os melhores alunos, mesmo os nacionais, e ser remetidos para uma posição marginal no sistema de ensino superior, com graves consequências na formação de recursos humanos do país e, portanto, na sua competitividade e desenvolvimento, temos rapidamente de encarar estas questões e de continuar a trabalhar pela melhoria da qualidade da investigação e da formação que fazemos, actividades inseparáveis na universidade como Bolonha bem afirma ${ }^{5}$.

Em articulação com esta linha de orientação coloca-se a questão de privilegiar certas áreas temáticas e o modo de articular a investigação e o ensino. Como conciliar o princípio da liberdade de pesquisa e de formação com a aposta nos temas em que somos fortes para continuar a aprofundá-los e, por isso, oferecer uma especialização, mesmo que eventualmente só a nível de $2 .^{\circ}$ ciclo? Em vez de continuar com a preocupação de cobrir toda a diversidade de campos cultivados pela Geografia, pode ser vantajoso escolher alguns, não muitos, e de preferência que apontem para nichos de mercado, mesmo se esta opção é difícil e exige ponderação.

Esta posição sobre as linhas de investigação a privilegiar pode ter consequências no desenho do curso em termos de equilíbrio entre a necessidade de abertura, associada a uma formação ecléctica susceptível de exercícios profissionais variados, principalmente a nível do $1 .^{\circ}$ ciclo, e uma especialização temática, para nichos do mercado, alicerçada na investigação desenvolvida. Mas, principalmente, obriga a 'negociar' entre temas de pesquisa e matérias de ensino na distribuição do tempo dos docentes-investigadores e a procurar equilíbrios entre a docência de temas gerais e aquela associada à investigação estreita de um assunto.

Além disso, na configuração do currículo, parece importante trabalhar temas com relevância social, como as questões da cidadania, do ambiente, do alojamento, da intervenção comunitária, do planeamento territorial a várias escalas, e do desenvolvimento e gestão do território, valorizando precisamente a contribuição da Geografia para estes problemas.

Para além de contribuir para o avanço do conhecimento e de propiciar formação, a universidade, enquanto comunidade escolar, tem a responsabili-

5 2. ${ }^{\circ}$ Princípio fundamental da Magna Carta da Universidade. Bolonha, 18 Set.1988. 
dade social de formar os cidadãos de amanhã. A Geografia está particularmente vocacionada para corresponder a finalidades como as que os colegas do departamento de Geografia da Universidade de Liège, com muita pesquisa feita no domínio da educação geográfica, tanto no secundário como no superior, enunciam (ser confiante, desenvolver a personalidade, ser cidadão responsável, cultivar a aprendizagem ao longo da vida, contribuir para a sociedade democrática e a emancipação social) e das quais fazem derivar as competências que os alunos devem possuir no fim dos estudos superiores.

Outra linha a explorar prende-se com a possibilidade de oferecer, no segundo ciclo de estudos, cursos em parceria com instituições estrangeiras prestigiadas e a introdução do inglês como língua de comunicação nalgumas unidades, por exemplo na leccionação de alguns seminários e aceitação de trabalhos nesta língua.

\section{EMPREGABILIDADE, COMPETÊNCIAS E ESPECIALIZAÇÃO}

A declaração de Bolonha prevê que «o grau conferido após o $1 .^{\circ}$ ciclo será também relevante para o mercado europeu de trabalho como nível apropriado de qualificação». Isto tem gerado confusão entre profissionalização e empregabilidade.

A questão da empregabilidade dos diplomados e das competências que eles possuem relaciona-se com o tipo de actividade profissional a que se destinam e, portanto, com os vários requisitos profissionais e remete, no essencial, para a diferença que deve caracterizar os dois subsistemas do ensino superior português: o universitário e o politécnico. Enquanto o politécnico em 3 anos forma profissionais especializados, nalguns casos com grande facilidade em encontrar um emprego mas que passados uns anos poderão ter dificuldades (no mercado de trabalho) se as suas competências especializadas forem ultrapassadas, a universidade mais dificilmente o fará. Alguns cursos universitários optaram mesmo pelo esquema $0+5$ ou $0+6$, no caso da medicina, sem saída intermédia de $1 .^{\circ}$ grau, uma vez que consideraram que a formação que poderiam dar a esse nível já era fornecida por outras escolas com ensino na área da saúde.

A empregabilidade, pelo menos nas Faculdades de Letras e Ciências Sociais e Humanas está associada a uma formação académica generalista (entendendo isto essencialmente como assente em competências transferíveis), interessante para um leque bastante alargado e diversificado de actividades profissionais e não pode confundir-se com uma especialização profissional, que só poderá ser adquirida, pelo menos com profundidade, a nível de $2 .^{\circ}$ ciclo. O caracter 'aberto' não deve contudo ser impeditivo de alguma especialização para alunos já direccionados para um determinada actividade profissional.

Os problemas principais que o modelo de curso coloca são sempre os mesmos em todas as reformas ou reestruturações que temos presenciado: o conteúdo do núcleo que deve assegurar a base de formação, a vantagem numa 
especialização relativamente precoce e o peso e papel das opções. Se o curso tiver apenas o núcleo básico e opções, é o leque destas que define a especialização ou a sua ausência. Desde os anos 70 que as reestruturações do curso de Geografia na FLUL visam também dar uma preparação profissional mais sólida e mais dirigida para saídas profissionais relacionadas com o ordenamento do território. Na reforma de 1978 isso verifica-se a nível do reforço das componentes de métodos, designadamente estatística e representação gráfica, depois, em 1984 com a criação de uma variante em planeamento regional e local. Em 1985, GASPAR escreve precisamente que esta variante se destina "fundamentalmente a formar técnicos para os domínios do planeamento regional e local» (sublinhado nosso). Na reforma de 1987 são criadas duas licenciaturas a de Ensino da Geografia e a de Planeamento Regional, esta com duas variantes (Física e Humana), enquanto na de 1998 se volta à licenciatura em Geografia agora com cinco variantes. Para além do Ensino e do Ordenamento do Território, surge então a de Urbanismo e a de Sistemas de Informação Geográfica por se ter verificado que se tratava de campos em grande expansão e com boas potencialidades para dar trabalho a geógrafos. A continuada diversificação de saídas profissionais tem-se reflectido na organização do curso que procura responder, embora sempre com atraso, às oportunidades do mercado de trabalho. Esta situação combinada com o encurtamento do $1 .^{\circ}$ ciclo universitário de 4 para 3 anos volta a colocar no primeiro plano a questão da especialização.

Com o actual modelo de variantes conseguiu-se contemplar, pela primeira vez no currículo, algumas disciplinas obrigatórias de especialização a par de outras opcionais, que teoricamente deviam reforçar aquela ou contrariá-la, no caso dos alunos que optassem por uma formação generalista. No entanto, a permutabilidade entre ambas acaba por anular a intenção de diferenciar as variantes, produzindo alunos sensivelmente com o mesmo tipo de formação, independentemente da variante que escolheram

De um modo geral os estudantes que frequentavam o curso de Geografia na FLUL em 2001-2002 estavam preocupados com as saídas profissionais e a adequação da formação ao mercado de trabalho, embora considerassem positiva a existência de variantes e mesmo o seu conteúdo programático, enquanto os docentes admitiam que tanto a estrutura curricular como a preparação para o mercado de trabalho eram pontos fortes do curso (BARATA SALGUeiro et al., 2003). No balanço feito pela variante de Ensino de Geografia, a mais especializada e orientada em termos profissionais, defende-se contudo a vantagem em possibilitar aos alunos o contacto com a prática profissional, portanto com as escolas e situações de sala de aula, antes do estágio pedagógico.

A estrutura dos cursos universitários não técnicos debate-se com um dilema que resulta da pressão dos estudantes (e provavelmente das famílias) para que os cursos tenham um perfil profissionalizante, uma articulação com o mercado de trabalho, que facilite a inserção profissional, e mesmo da consciência de serviço da universidade que, ao promover a elevação do nível cultural da população, não se pode alhear das necessidades da sociedade e do mercado de 
trabalho, por um lado. Por outro lado, liga-se com o aumento da flexibilidade no mercado de trabalho e a dinâmica dos sistema de emprego que aconselham a dotar os estudantes de capacidade de inserção em actividades profissionais relativamente diversificadas e a propiciar-lhes ferramentas que lhes permitam gerir a sua actividade profissional, que se vai moldando no tempo, continuando a formação ao longo da vida. Neste quadro, mais do que discutir nomes de disciplinas, assume maior relevância a discussão sobre as competências que devem adquirir e o tipo de especialização a fornecer pelos cursos nos diferentes ciclos e mesmo a ligação com as actividades profissionais, por meio de estágios, ou outras.

A articulação com a prática profissional tem sido tentada através de estágios com carácter curricular apenas na variante de ensino. Nas outras variantes tem-se aproveitado o seminário do último ano para aproximar os alunos de realidades profissionais, através de estadias ou visitas frequentes a departamentos, aproveitando esse contacto para estudar um problema que se torna o centro do trabalho de fim de curso e que pode ter uma maior ou menor componente de aplicação. Esta experiência parece ser do agrado dos alunos e portanto merece desenvolvimento e expansão, por exemplo através de programas de estágio pós-licenciatura remunerados.

Alguns autores, designadamente J. V. CosTA (2005), defendem que Bolonha implica também uma nova maneira de pensar o ensino, um novo paradigma que inclui, entre outros aspectos, uma tipologia diferente de educação académica e vocacional; formação académica de banda larga, ênfase na aquisição de competências, primado da aprendizagem sobre o ensino tradicional. Não há dúvida que o enfoque nestes dois últimos aspectos, que aliás decorrem um do outro, nos vai obrigar a pensar a estrutura dos cursos e a prática de ensino de forma completamente diferente.

A questão das competências, que se pretende venham a desempenhar um papel central na reformulação dos cursos e no modo de pensar o ensino, tem vindo a merecer a atenção dos professores num processo que na geografia está ainda numa fase pouco avançada. Existe uma grande convergência entre learning outcomes (aprendizagens) e competências. No projecto Tuning (GonZALEZ e WAGENAAR, coord., 2005) os learning outcomes são formulados em termos de competências, avaliados por níveis de desempenho e definem o que o formando sabe e é capaz de fazer no final da experiência de aprendizagem (especificam os requisitos mínimos para a con-cessão de créditos) de modo que a mesma competência pode ser desenvolvida a diferentes níveis de desempenho.

Há competências específicas de uma determinada área de saber e competências genéricas que representam uma combinação dinâmica de atributos, capacidades e atitudes. As competências genéricas apontadas, de um modo geral, para um diplomado com o primeiro ciclo da universidade referem:

- capacidade de análise e de síntese; capacidade de comunicação oral e escrita; conhecimento de língua(s), e capacidade de usar as TICs, tecnologias de comunicação e informação; 
- capacidade de se adaptar a situações novas, de resolver problemas, de aplicar os conhecimentos à prática;

- capacidade de trabalhar em equipa, designadamente pluridisciplinar, liderança, organização, sentido de responsabilidade, espírito empreendedor, criatividade;

- conhecimento geral sobre a sua área de formação e conhecimento da prática profissional na sua área.

Já nas competências específicas para a Geografia se encontra maior diversidade. Algumas consultas ${ }^{6}$ permitem para já agrupá-las nos seguintes conjuntos:

- compreender e interpretar paisagens, o significado das relações espaciais e construir modelos e esquemas espaciais a diferentes escalas;

- perceber as diferentes formas de organização do espaço, a diversidade e interdependência de regióes e lugares, os mecanismos que conduzem à segregação espacial, e a natureza das mudanças que os afectam;

- recolher, comparar, analisar e apresentar a informação geográfica usando diferentes técnicas e perspectivas em Geografia;

- aplicar e perceber os conceitos geográficos e comunicar (escrita e oralmente) ideias, princípios e teorias geográficas.

A título de exemplo, podemos referir o site da universidade de Liège onde se refere que estas competências devem habilitar os jovens a saber usar o território, a participar em debates sobre planos, a gerir o seu espaço local e comunitário, a avaliar diversas opções com impacto espacial, como sejam diferentes meios de transporte, escolha de bens e lugares de consumo ou outros.

Este breve enunciado de competências é suficientemente revelador do desafio que preparar uma reestruturação do curso nesta base comporta. Em que medida e de que modo cada disciplina contribui para o desenvolvimento de que competências (gerais e especificas)?

\section{MÉTODOS DE ENSINO E ORGANIZAÇÃO DOS CURSOS}

Precisamente um dos principais desafios relacionados com Bolonha reporta-se à organização dos cursos e aos métodos de ensino mais focados em competências e valorizadores das aprendizagens.

$\mathrm{Na}$ avaliação do ano lectivo 2001/02, apesar de se fazer um balanço bastante positivo da organização do curso, considerando-se que os objectivos estão

6 Site da rede Herodot, Eunet, Programa Tuning da UE, universidades britânicas e de Liège principalmente. 
a ser alcançados, reconhece-se que se podem introduzir melhorias. Assim, é mencionado, principalmente pelos estudantes e pelos responsáveis pelas variantes de Ensino e Urbanismo, o excesso de disciplinas e ou matérias, traduzido numa carga horária muito pesada, com horários pouco adequados e sobrecarga de trabalhos, deixando pouco tempo para efectuar leituras e para pensar. Os professores referem também o elevado número de alunos por turma e a falta de articulação ou sobreposição de conteúdos, enquanto todos destacam a necessidade de dispor de mais tempo para trabalhos de campo, de reforçar a componente de SIG, de aumentar o número de opções e o leque das ofertas pois, com demasiada frequência, as opções respondem apenas às necessidades em termos quantitativos. Portanto, parece haver uma convergência de opiniões no sentido de introduzir correcções que visem reduzir o número de horas de aula, dispor de conteúdos mais articulados, de mais opções e mais diversificadas, menos exercícios, mas mais trabalhos de campo e SIGs, menos alunos por turma.

O número de alunos é certamente um dado importante para a organização do ensino pois certos modelos não são aplicáveis a grandes turmas. A reivindicação da redução dos alunos por turma é uma persistência no discurso dos professores que não questionam o método de ensino e responsabilizam o número de alunos, em conjunto com a sua falta de preparação, pelos problemas de fracasso pedagógico, insucesso, desinteresse.

Tradicionalmente o ensino universitário distribuía-se entre aulas teóricas e aulas práticas. As primeiras essencialmente expositivas, por vezes em anfiteatros com grande número de estudantes, podiam dispor de uma 'sebenta' hoje, por conversão às TIC, substituída por uma sucessão de diapositivos de power point, para ajudar o trabalho dos alunos. Estas sessões são combinadas com aulas práticas de menor número de alunos onde se retoma a matéria, tiram dúvidas, se fazem exercícios ou se passam exercícios para os estudantes fazerem. Laboratoriais ou de contacto com modelos na Faculdade de Ciências, tinham na leitura de mapas ou no comentário de textos, mais frequente em Letras, o equivalente na Geografia. A avaliação era feita com base em exames que testavam a capacidade dos estudantes em reproduzir a sebenta ou os apontamentos das aulas e uma ou outra leitura obrigatória, muitas vezes apenas os textos discutidos nas aulas e constantes do respectivo caderno de apoio, a que se juntava a execução de algum exercício prático.

Clout (2003) considera que é quase impensável prescindir das aulas teóricas para grandes turmas para o $1 .^{\circ}$ ano, na actual situação financeira das universidades no Reino Unido. Provavelmente o mesmo acontecerá em Portugal; a questão não é tanto negar as aulas teóricas expositivas mas descobrir como integrar esta aula-conferência com outros tipos de aprendizagem que exijam mais do aluno do que memorizar o discurso do professor. De modo semelhante também há que reconhecer que muitas aulas práticas são uma perda de tempo e precisam igualmente de ser repensadas.

A minha experiência de ensino da Geografia Urbana para níveis diferentes e com formas de aulas diversas leva-me a pugnar por uma flexibilidade que 
permita organizar o tempo à medida das necessidades, pois parece-me errado dividir o tempo lectivo rigidamente ao meio entre sessões teóricas e sessões práticas, ainda por cima com duração igual de 2 horas, quando a aprendizagem de uma matéria pode ser distribuída por diferente tipos de actividades, desde a aula expositiva onde se apresenta a problemática, a exercícios de campo, desde leituras à elaboração de relatórios, que não são iguais para todos os capítulos de uma mesma disciplina.

Bolonha é uma óptima oportunidade para flexibilizar o tempo de aulas e favorecer o sucesso escolar com maior recurso a aprendizagens orientadas de tipo formativo, na medida em que dissocia o número de créditos do número de horas de aula, mas se não houver rigor e honestidade na planificação dos trabalhos pode tornar-se numa perigosa mistificação. Métodos mais flexíveis de ensino exigem também maior responsabilização dos actores e avaliações independentes.

Em contraste com o ensino informativo, hoje em dia fala-se muito em métodos formativos centrados no investimento na auto formação, que pedem mais trabalho aos alunos, seja individual, seja em pequenos grupos; o que se pretende é que aprendam a equacionar um problema, compreendê-lo e explicálo através de diferentes tipos de abordagens, recorrendo à teoria e às ferramentas de análise geográfica, a aplicar correctamente métodos de recolha e tratamento da informação pertinente, a discutir hipóteses credíveis para a sua solução, tendo em atenção os diferentes instrumentos existentes (financeiros, legais, e outros), a apresentar os resultados tanto por escrito como oralmente. Provavelmente, todos estarão de acordo com estes objectivos que sempre estiveram presentes na acção pedagógica. A diferença, e não é pequena, está no ênfase colocado na auto-formação, na maior autonomia do estudante, na alteração do papel do professor acentuando a função de orientador. A aprendizagem exige o investimento pessoal na leitura, na aplicação, na interrogação e procura de explicações.

Se no primeiro ano os alunos devem ter possibilidade de fazer pequenos exercícios em sala de aula ou no campo, desde compreender um texto a elaborar e aplicar um questionário, fazer um corte topográfico ou uma planta funcional, progressivamente deviam fazer trabalhos mais complexos e que exigem mais tempo, embora sujeitos à apresentação de materiais que seriam corrigidos rapidamente, sem que isso implicasse necessariamente uma aula formal.

O tipo de aulas e de participação dos alunos deve portanto mudar ao longo do curso e o tipo de créditos associados ao processo Bolonha, os ECTS ${ }^{7}$, facilita imenso este caminho. Temos de definir o papel e o peso das aulas teóricas bem como a existência de práticas ou outras modalidades de aprendizagem nos vários anos do curso, para além do número de cadeiras e dos seus objectivos,

\footnotetext{
7 European credit transfer system.
} 
naturalmente. Em sede de coordenação devem ser definidos o tipo de exercícios a fazer em cada nível de ensino, o tipo de textos a ler e o modo de avaliação.

Fomentar a autonomia, mesmo na própria elaboração curricular, deve passar também por uma informação e planificação atempadas e cuidada das actividades. Por exemplo, no que respeita ao número de opções a economia de meios só permitirá alterar a actual situação se não se oferecer todos os anos as mesmas disciplinas mas houver alguma constância na rotatividade para que os estudantes possam fazer os seus planos para o conjunto do curso e, por outro lado, se houver maior abertura a nível da Faculdade/ Universidade de modo a que os departamentos ofereçam disciplinas de opção que sirvam os outros ${ }^{8}$. Isto liga-se directamente com a necessidade de introduzir níveis ou qualificativos nas várias disciplinas e com a colaboração entre departamentos, situação de que a Geografia tem grande experiência.

O ensino da geografia universitária recorreu sempre a outras disciplinas 'auxiliares' ou 'complementares' e durante muito tempo a organização do curso entre a Faculdade de Ciências, com um peso que se veio a reduzir, e a de Letras ${ }^{9}$ traduzia a resposta possível, em termos de posicionamento universitário, à posição da Geografia entre as ciências físico-naturais e as ciências sociais ou humanas ${ }^{10}$.

A crescente especialização dos ramos de conhecimento e a diminuição da colaboração entre os docentes acompanharam a tendência para 'internalizar' o ensino das matérias consideradas indispensáveis à formação dos geógrafos, sob o argumento de melhor controlar o interesse dos conteúdos, a sua aplicabilidade. Se docentes de Geografia, Geologia e História saíam juntos para o campo, os seus interesses e especificidades tornavam-se reciprocamente evidentes, as linguagens próprias eram facilmente entendíveis. Quando este tipo de colaboração cessou, se reduziu, ou perdeu, houve que institucionalizá-la, substituindo o contacto pela regra negociada. Constatou-se então o menor interesse de alguns ensinos, demasiado teóricos ou efectuados a uma escala menos útil para o geógrafo, e cresceu a tendência para a internalização dos saberes, seja porque essas matérias passaram a ser leccionadas especialmente a geógrafos em turmas especiais, ainda na Faculdade de Ciências, e já na de Letras, no caso das psico-pedagógicas ou da economia, ou mesmo leccionadas por geógrafos, como sucede actualmente com a geologia, a cartografia e os métodos estatísticos.

8 Teoricamente qualquer disciplina da FLUL é de opção para os alunos de outros cursos mas na prática são levantados inúmeros obstáculos aos corajosos que se aventuram a inscrever. Com efeito, a nossa visão de ensino sequencial dificulta a vida de quem queira fazer uma matéria especializada ou de especialização intermédia sem possuir as básicas.

92 anos na Faculdade de Ciências com 8 ou 9 cadeiras, mais tarde apenas umas 5, e 3 em Letras onde estava a Geografia e se faziam 2 obrigatórias em História (Pré-História e História de Portugal), mais 2 ou 3 de opção nesse departamento, por falta de outras alternativas, sem falar nas 2 Antropologias integradas na Geografia.

10 Ver a este propósito a reflexão de Ilídio do Amaral sobre as reformas curriculares. 
O aumento da mobilidade, a necessidade de gerir com melhor rendimento os recursos humanos existentes e os desequilíbrios entre o número de alunos e professores entre os vários departamentos e escolas da universidade devem obrigar a inverter esta situação. Esta opção exige grande colaboração, esclarecimento e um ensino mais diversificado e destinado a clientelas diferenciadas introduzindo, por exemplo, níveis nas disciplinas com repercussões no tipo de matéria e do seu aprofundamento. Tal como uma disciplina semestral não pode ter a mesma matéria que a anual que a antecedeu, o ensino da estatística descritiva, do inglês ou da geografia de Portugal poderá não ser igual para alunos desse curso (Matemática, Anglo Americanos ou Geografia) e para os outros, e terá vantagens em ser diferenciado por níveis de profundidade.

Da nossa capacidade de pôr as questões e de lhes encontrar respostas adequadas no quadro europeu deriva o sucesso da Geografia portuguesa na universidade nos próximos anos. No contexto das mudanças que se avizinham e do apelo continuado para abrir o curso a novas orientações profissionais, importa ainda sublinhar a importância da formação de professores pois, como todos sabemos, se o ensino não for assegurado por docentes bons e qualificados nos níveis básicos, não haverá alunos de geografia na universidade.

\section{BIBLIOGRAFIA}

Amaral, I. (1973-74) - Livro-Guia do Curso de Geografia. Lisboa, Faculdade de Letras, (policopiado).

AmARAL, I. (1980) - Apontamentos para a história do ensino universitário de Geografia em Portugal. II Colóquio Ibérico de Geografia, Comunicações, Lisboa, vol I, 1982: 135-138.

Amaral, I. (1983) - Geógrafos e Geografia na Faculdade de Letras de Lisboa. Revista da Faculdade de Letras: 68-82.

Amaral, I. (1984) - As Faculdades de Letras na Universidade Moderna. Separata da Revista da Faculdade de Letras, n. ${ }^{\circ} 1$, 5. $^{\mathrm{a}}$ série: 95-109.

Barata Salgueiro, T. (2003) - L’enseignement universitaire au Portugal. Géographes Associés, 27: 37-43.

Barata Salgueiro, T.; Ferreira, D. B.; Simões, J. M.; Cachinho, H. P. (2003)-Relatório de Autoavaliação de Geografia. Ano lectivo 2001-2002. Lisboa, FLUL (policopiado).

CAChinho, H. (2005) - Formação inicial na Educação Geográfica. Actas do 2. ${ }^{\circ}$ Colóquio Ibérico de Didáctica da Geografia (no prelo).

Claudino, S.; Munoz I.; TorRente, X. (1991) - A formação e a actividade profissional dos geógrafos em Lisboa, Barcelona e Copenhaga. V Colóquio Ibérico de Geografia. Actas, Ponencias y Comunicaciones. León: 69-83.

Clout, H. (2003) - Design of Geography Programmes in the UK. An example in the spirit of Bologna. Géographes Associés, 27: 101-109.

Costa, J.V. (2005) - Bolonha em Portugal. A grande confusão, Jornal Público, 25 Janeiro, 2005, p. 7 e http://pwp.netcabopt/jvcosta/ 
Documentos do Processo de Bolonha, Disponíveis no site do CRUP: www.crup.pt

Gaspar, J. (1985) - A Variante de Geografia e Planeamento Regional e Local da licenciatura em Geografia. Separata da Revista da Faculdade de Letras, n. ${ }^{\circ} 3$ 5. $^{a}$ série: 219-228.

Gaspar, J.; Medeiros, C. A. (1982) - A organização do curso de Geografia na Faculdade de Letras de Lisboa depois do 25 de Abril, 2. ${ }^{\circ}$ Colóquio Ibérico de Geografia, Comunicações, Lisboa, $1 .^{\circ}$ vol.: 181-194.

Gonzalez, J.; WagenaAR, R. (coord.)-Projecto Tuning Educacional Structures in Europe, 1. ${ }^{\text {a }}$ fase. Disponível em: www.relint.deusto.es/TUNINGProject/ (consultado em Março de 2005). 